Joachim Höpfner

\title{
Atmospheric, oceanic and hydrological contributions to seasonal variations in length of day
}

\author{
Paper presented at the XXV General Assembly \\ European Geophysical Society \\ Nice, France, 25-29 April 2000
}

Scientific Technical Report STR00/05 


\title{
Atmospheric, oceanic and hydrological contributions to seasonal variations in length of day
}

\author{
Joachim Höpfner \\ GeoForschungsZentrum Potsdam, Division 1: Kinematics and Dynamics of the Earth,Telegrafenberg, D-14473 \\ Potsdam, Germany; E-mail: ho@gfz-potsdam.de
}

\begin{abstract}
The annual and semiannual residuals derived in the axial angular momentum budget of the solid Earthatmosphere system reflect significant signals. They must be caused by further excitation sources. Since, in particular, the contribution for the wind term from the atmospheric layer between the 10 and $0.3 \mathrm{hPa}$ levels to the seasonal variations in length of day (LOD) was still missing, there is the need to extend the top level into the upper stratosphere up to $0.3 \mathrm{hPa}$. Under the conservation of the total angular momentum of the entire Earth, variations in the oceanic angular momentum (OAM) and the hydrological angular momentum (HAM) are further significant excitation sources at seasonal time scales. Focusing on other contributions to the Earth's axial angular momentum budget, we use the following data in this study: Axial atmospheric angular momentum (AAM) data derived for the 10-0.3 hPa layer from 1991 to 1997 for computing the missing wind effects, axial OAM functions as generated by oceanic general circulation models (GCMs), namely for the ECHAM3 and the MICOM models, available from 1975 to 1994 and 1992 to 1994, respectively, for computing the oceanic contributions to LOD changes, and, concerning the HAM variations, the seasonal estimates of the hydrological contribution as derived by Chao and O'Connor (1988). Using the vector representation, we show that the vectors achieve a close balance in the global axial angular momentum budget within the estimated uncertainties of the momentum quantities on the seasonal time scales.
\end{abstract}

Key words: Earth's rotation, LOD (length of day), AAM (atmospheric angular momentum), OAM (oceanic angular momentum), HAM (hydrological angular momentum), contributions to LOD changes, global axial angular momentum budget, balance on the seasonal time scales

\section{Introduction and objective}

Under the conservation of the total angular momentum of the entire Earth, there is the angular momentum exchange between the solid Earth, atmosphere, oceans, hydrosphere, liquid core, and other geophysical fluids such as the melting of glaciers, sea level rise, and post-glacial rebound. Concerning the solid Earth, i. e., its crust and mantle, changes in the rotation rate, and hence in the length of day (LOD), and polar motion (PM) reflect this angular momentum exchange. Here, the dominant forcing is of atmospheric origin on interannual, seasonal and intraseasonal time scales.

As described by Barnes et al. (1983), effective atmospheric angular momentum (AAM) functions related to the Earth rotation are used to calculate numerically AAM time series by the world's meteorological centers. Here, the equatorial components $\chi_{1}$ and $\chi_{2}$ are associated with the excitation of PM, and the axial component $\chi_{3}$ is associated with changes in LOD. In particular, variations in the axial angular momentum of the atmosphere are mirrored clearly in Earth's rotation signals. At seasonal frequencies, there are the largest signals. Therefore, a very large number of studies were concerned with the seasonal imbalances in the axial angular momentum budget of the solid Earth-atmosphere system. For a review of the state of the art in studying the Earth's axial angular momentum balance at intraseasonal through interannual and decadal time scales, see, e.g., Hide and Dickey (1991) and Rosen (1993), respectively, or, for a recent review restricted to the progress at seasonal time scales, Höpfner (1998). As found in the studies such as Naito and Kikuchi (1990), Rosen and Salstein (1991), Dickey et al. (1993), Höpfner (1996, 1997, 1998a, b, 2000), the annual and semiannual residuals derived in different systems reflected significant signals, which must be caused by additional excitation sources in the complex Earth system. In this study, therefore, we focus on other contributions to the Earth's axial angular momentum budget at seasonal time scales. 
Only contributions with regard to air and water are likely to be important on seasonal to subseasonal time scales, but the details remain still very uncertain. Concerning the water mass redistributions in the global hydrosphere, they introduce variations in oceanic angular momentum (OAM) and hydrological angular momentum (HAM). Using the Inverted-Barometer (IB) approximation, AAM calculations include an oceanic contribution. The estimated IB effect is based on the assumption of an isostatic response of oceans to barometric pressure changes. But the actual oceanic contribution is much more complicated than that computed using the IB approximation. Therefore, the determination of the oceanic contribution required a model of the dynamic response of the oceans to pressure changes which is more sophisticated.

Relating to hitherto existing studies in this field, it is suitable to briefly review as follows: The contribution from surface water storage to seasonal changes in LOD was estimated by Chao and O'Connor (1988). Based on an oceanic general circulation model, Ponte (1990) showed that the oceans may play an important role in accounting for the remaining LOD variation after removing the AAM contributions. Dickey et al. (1993) examined the oceanic contribution in the light of the angular momentum balance between atmosphere and solid Earth at seasonal frequencies. Moreover, Chen et al. (1997) derived results by means of the total AAM, OAM and HAM contributions and the LOD changes, and Marcus et al. (1998) similar but without the HAM contribution. Also studied Johnson et al. (1999) the seasonal and biennial oceanic signals in comparison with the corresponding residuals computed as differences from LOD changes and AAM contributions, again whithout considering the HAM signal. Based on the constant-density model of Gaspar and Ponte (1997), Ponte (1997) calculated oceanic excitation functions for LOD and analyzed the results as a function of the frequency band, in particular the variances calculated by summing the squared amplitudes of the Fourier harmonics in the seasonal, intraseasonal, submonthly, and daily bands. Judging the results based on their intercomparisons, we can say that definitive results and conclusions are not yet available, and this suggests a continuation of studies in the field.

Concerning the data to be used in this study, some points should be noted. To compute the AAM functions, each component is partitioned into wind and pressure terms according to the two excitation origins. Concerning the wind terms represented by volume integrals of winds over the depth of the atmosphere at different pressure levels, the top level used in the atmospheric general circulation models (GCMs) of the meteorological centers varies and is, at best, $10 \mathrm{hPa}$ which account for about $99 \%$ of the atmosphere's mass. Consequently, referred to the AAM systems with 10 -hPa top level, the contribution for the wind term from the atmospheric layer between the 10 and $0.3 \mathrm{hPa}$ levels to the LOD changes was still missing in previous studies including our own (Höpfner 1996, 1997, 1998a, b, 2000). Therefore, there is the need to extend the top level into the upper stratosphere up to $0.3 \mathrm{hPa}$. AAM data derived for the $10-0.3 \mathrm{hPa}$ layer are available from 1991 to 1997 (D. A. Salstein and P. Nelson, private communication, 1999), to investigate the missing wind effects at seasonal time scales.

Then, concerning the non-atmospheric axial angular momentum budget for the Earth, significant oceanic contributions should be manifest as changes in LOD. Accounting for oceanic effects on Earth rotation parameters requires numerical integration of gridded fields from oceanic analysis systems. In a way that is analogous to the calculations from atmospheric GCMs, this must be done using oceanic GCMs together with data assimilation. For our computing the oceanic contributions to LOD changes, OAM functions as generated by two oceanic GCMs, in particular for the ECHAM3 and the MICOM models, and available from 1975 to 1994 and 1992 to 1994, respectively, are used (M. Thomas, private communication, 1999; S. L. Marcus, private communication, 1999). OAM functions that represent LOD and PM excitations consider both variable currents and mass redistributions of the oceans.

Variations in HAM associated with continental storage of water, ice, and snow are another excitation source of LOD changes, but these have been less well resolved. The reasons for this are a lack of pertinent observations on the one side and the difficulty in modeling the effects in a realistic manner on the other side. As mentioned above, Chao and O'Connor (1988) estimated the seasonal contributions of the surface water storage. Since HAM data were not available, we used these estimates together with those derived for the wind term from the atmospheric layer between the 10 and $0.3 \mathrm{hPa}$ levels and those derived from the OAM data in our vector representations to show to what extent a balance in the global axial angular momentum budget on the seasonal time scales is achieved. Before dealing with these topics in detail, in Section 2, it is appropriate to briefly describe the relationship between changes in LOD and their excitations.

\section{Relations for LOD changes}

As noted above, the present study is restricted to the global axial angular momentum budget at seasonal time scales, where we should consider the atmospheric, oceanic and hydrological excitations that contribute to the LOD changes. In our case, therefore, the total angular momentum of the Earth system is

Total_AM $=$ Solid_Earth_AM+AAM+OAM+HAM 
with AM abbr. for angular momentum. That is, assuming the solid Earth, the atmosphere and the hydrosphere form a closed dynamical system, then changes in AAM, OAM and HAM about the polar axis relative to an Earth-fixed frame must be reflected by compensating changes in the axial AM of the solid Earth. Referred to the LOD changes, the relation reads

$L O D=L O D_{a t m}+L O D_{\text {ocean }}+L O D_{\text {hydrol }}$

where $L O D_{a t m}$ is the atmospheric contribution to LOD inferred from AAM, $L O D_{\text {ocean }}$ the oceanic contribution to LOD inferred from OAM, and $L O D_{h y d r o l}$ the hydrological contribution to LOD inferred from HAM. In other words, the changes in the axial angular momentum of a component of the Earth are accompanied by equal, but opposite, excitations of LOD changes.

LOD is the only quantity that is directly measurably, whereas the excitation contributions to changes in LOD must be indirectly inferred. For the atmosphere and oceans, there are AAM and OAM calculations simulated by atmospheric and oceanic GCMs, respectively. In contrast, HAM estimates are not so available.

Concerning the seasonal imbalances in the axial angular momentum budget of the solid Earth-atmosphere system presented in our previous papers (Höpfner 1996, 1997, 1998a, b, 2000), it should be noted that, if the results are referred to the $L O D_{a t m}$ systems with 10 -hPa top level, the relation (2), with

$L O D_{a t m}=L O D_{a t m}(1000-10)+L O D_{a t m}(10-0.3)$,

becomes

$\left\{L O D-L O D_{a t m}(1000-10)\right\}=L O D_{a t m}(10-0.3)+L O D_{\text {ocean }}+L O D_{\text {hydrol }}$

where the numbers added to $L O D_{a t m}$ are to reflect the lower and upper levels in the atmosphere in hPa used in calculating the values of the wind terms.

Equation (4) is the basis of the following considerations and estimations. Since this equation is given in the time domain, but the results derived for the portions at seasonal time scales are time series over different time intervals, it is necessary to use their amplitude and phase estimates or their Fourier coefficients. Interpreting geometrically, these representations are vectors. Therefore, arithmetic operations with them can be realized as vector operations. In Section 3, preparatory, we make available the amplitude and phase estimates of the seasonal imbalances in the axial angular momentum budget of the solid Earth-atmosphere system for this purpose.

\section{Seasonal dicrepancies in the solid Earth-atmosphere axial angular momentum budget}

For the term $\left\{\right.$ LOD - $\left.L O D_{a t m}(1000-10)\right\}$ in equation (4), we refer to our previous papers (Höpfner 1996, 1997, 1998a, b, 2000). At seasonal time scales, there are the residual oscillations derived as difference series between LOD and $L O D_{a t m}(1000-10)$ in different systems. These residual time series are processed with respect to the amplitude and phase estimates, including their standard deviations, by using two methods: the one based on the maximum, zero crossing and minimum of a periodic function as described in Höpfner $(1997,1998 \mathrm{~b})$ and that of the least-square fit for annual and semiannual sinusoids, respectively. Table 1 gives the results obtained for the different LOD- $L O D_{a t m}(1000-10)$ systems and for transfers between the $L O D_{a t m}$ systems. Here, the abbreviations and notations used are: IERS - International Earth Rotation Service, JPL - Jet Propulsion Laboratory, Pasadena; JMA - Japan Meteorological Agency, NCEP - U. S. National Centers for Environmental Prediction, NMC - U. S. National Meteorological Center, IB - Inverted Barometer, (IB) - for wind plus pressure term with IB response $\chi_{3}(\mathrm{~W})+\chi_{3}(\mathrm{P}+\mathrm{IB}),(\mathrm{P})$ - for wind plus pressure term without IB response $\chi_{3}(\mathrm{~W})+\chi_{3}(\mathrm{P})$.

It is worth remarking that the NMC and JMA input data are computed operationally, whereas the NCEP input data are obtained by reanalysis. Concerning the results derived by the two mentioned methods, see in Table 1 that the amplitude values obtained from our method are significantly larger than those from the least-square fit, whereas there is a good agreement of the phase values to each other. However, if the amplitude of a residual time series is rather small and its phase varies with time considerably, it is difficult to estimate optimally the phase. Relating to the amplitude, it is assessed that the results by using our method represent the better estimates. Therefore, if reliably calculated, we prefer these estimates in the further representations and considerations. Comparing the standard deviations for both methods, we judge the uncertainties derived from our method more realistically than those derived from the least-square fit for annual and semiannual sinusoids, respectively. 
Publication: Scientific Technical Report

No.: STR00/05

Author: J. Höpfner

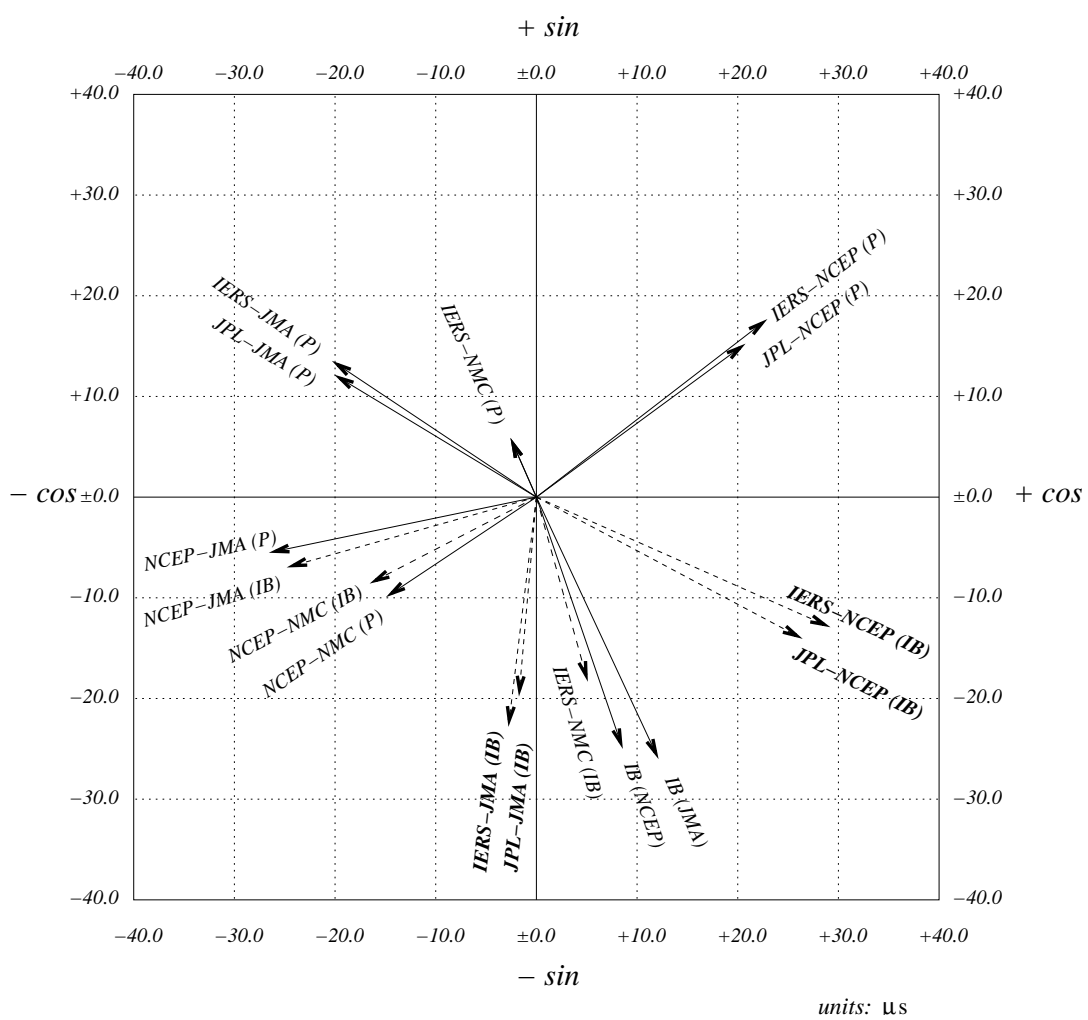

Figure 1. Vector representation of the amplitude and phase estimates of the annual LOD-LODatm (1000-10) residual time series in different systems. The vectors for a transfer between the $L O D_{a t m}$ systems are also shown

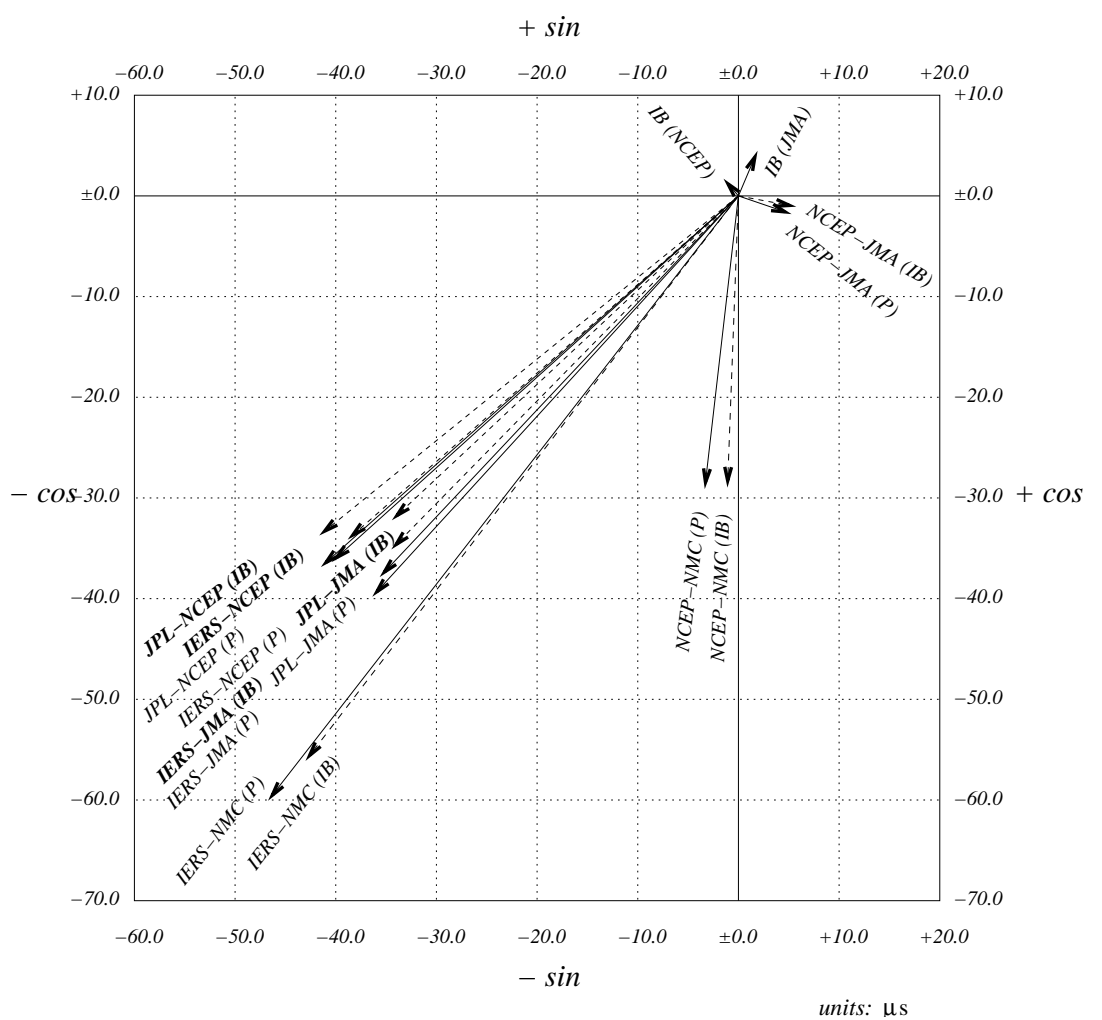

Figure 2. As for Fig. 1, but for the semiannual LOD- $L O D_{a t m}(1000-10)$ residual time series 
Publication: Scientific Technical Report

No.: STR00/05

Author: J. Höpfner

Table 1. Amplitude and phase estimates including the standard deviations of the seasonal residual oscillations derived as differences between LOD and $L O D_{a t m}(1000-10)$ time series in different systems. The phase angle with respect to the cosine convention refers to January 1 . Units are: Amplitude values in $\mu \mathrm{s}$, phase values in degrees

\begin{tabular}{|c|c|c|c|c|c|}
\hline \multirow[t]{2}{*}{ Referred to the systems } & \multirow[t]{2}{*}{ Time interval } & \multicolumn{2}{|c|}{ Results from our method } & \multicolumn{2}{|c|}{ Results from fit } \\
\hline & & Amplitude & Phase & Amplitude & Phase \\
\hline \multicolumn{6}{|c|}{ (a) Annual residual oscillation } \\
\hline \multicolumn{6}{|c|}{ Without IB response } \\
\hline IERS-NMC(P) & $1983 \ldots 1993$ & & & $6.49 \pm 0.40$ & $113.70 \pm 3.50$ \\
\hline IERS-JMA(P) & $1985 \ldots 1995$ & $24.47 \pm 3.01$ & & $16.76 \pm 0.26$ & $146.31 \pm 0.90$ \\
\hline JPL-JMA(P) & $1985 \ldots 1994$ & $23.54 \pm 2.47$ & $131.61 \pm 14.06$ & $18.63 \pm 0.25$ & $148.80 \pm 0.78$ \\
\hline IERS-NCEP(P) & $1980 \ldots 1995$ & $28.68 \pm 3.57$ & & $22.36 \pm 0.21$ & $36.74 \pm 0.54$ \\
\hline JPL-NCEP(P) & $1978 \ldots 1994$ & $26.02 \pm 2.54$ & $40.70 \pm 7.67$ & $21.32 \pm 0.20$ & $36.88 \pm 0.54$ \\
\hline \multicolumn{6}{|l|}{ With IB response } \\
\hline IERS-NMC(IB) & $1983 \ldots 1993$ & & & $19.10 \pm 0.38$ & $285.55 \pm 1.14$ \\
\hline IERS-JMA(IB) & $1985 \ldots 1995$ & $23.00 \pm 5.16$ & & $16.87 \pm 0.24$ & $263.89 \pm 0.81$ \\
\hline JPL-JMA(IB) & $1985 \ldots 1994$ & $19.97 \pm 3.37$ & $264.03 \pm 9.99$ & $16.87 \pm 0.23$ & $257.22 \pm 0.78$ \\
\hline IERS-NCEP(IB) & $1980 \ldots 1995$ & $31.99 \pm 3.39$ & & $29.27 \pm 0.18$ & $336.14 \pm 0.36$ \\
\hline JPL-NCEP(IB) & $1978 \ldots 1994$ & $30.02 \pm 3.03$ & $331.98 \pm 6.39$ & $28.43 \pm 0.17$ & $333.86 \pm 0.34$ \\
\hline \multicolumn{6}{|c|}{ For a transfer between the $L O D_{a t m}$ systems } \\
\hline NCEP-NMC(P) & $1983 \ldots 1993$ & & & $18.00 \pm 0.37$ & $213.62 \pm 1.18$ \\
\hline NCEP-NMC(IB) & $1983 \ldots 1993$ & & & $18.71 \pm 0.36$ & $207.39 \pm 1.08$ \\
\hline NCEP-JMA(P) & $1985 \ldots 1995$ & & & $27.19 \pm 0.23$ & $191.73 \pm 0.50$ \\
\hline NCEP-JMA(IB) & $1985 \ldots 1995$ & & & $25.83 \pm 0.21$ & $195.71 \pm 0.46$ \\
\hline $\mathrm{IB}(\mathrm{NCEP})$ & $1970 \ldots 1995$ & & & $26.50 \pm 0.05$ & $288.96 \pm 0.11$ \\
\hline IB(JMA) & $1985 \ldots 1995$ & & & $28.76 \pm 0.07$ & $294.99 \pm 0.14$ \\
\hline \multicolumn{6}{|c|}{ (b) Semiannual residual oscillation } \\
\hline \multicolumn{6}{|c|}{ Without IB response } \\
\hline IERS-NMC(P) & $1982 \ldots 1994$ & & & $75.95 \pm 0.26$ & $232.32 \pm 0.19$ \\
\hline IERS-JMA(P) & $1984 \ldots 1996$ & $53.99 \pm 2.31$ & $227.58 \pm 5.32$ & $51.24 \pm 0.22$ & $227.83 \pm 0.25$ \\
\hline JPL-JMA(P) & $1984 \ldots 1996$ & $52.04 \pm 2.19$ & $226.73 \pm 3.65$ & $50.83 \pm 0.19$ & $225.66 \pm 0.22$ \\
\hline IERS-NCEP(P) & $1980 \ldots 1996$ & $54.42 \pm 2.55$ & $221.99 \pm 5.72$ & $52.56 \pm 0.19$ & $220.89 \pm 0.21$ \\
\hline JPL-NCEP(P) & $1977 \ldots 1996$ & $55.55 \pm 2.63$ & $221.62 \pm 3.89$ & $54.81 \pm 0.17$ & $218.79 \pm 0.18$ \\
\hline \multicolumn{6}{|l|}{ With IB response } \\
\hline IERS-NMC(IB) & $1982 \ldots 1994$ & & & $70.95 \pm 0.26$ & $232.32 \pm 0.21$ \\
\hline IERS-JMA(IB) & $1984 \ldots 1996$ & $49.26 \pm 1.87$ & $225.52 \pm 6.77$ & $46.61 \pm 0.18$ & $225.84 \pm 0.22$ \\
\hline JPL-JMA(IB) & $1984 \ldots 1996$ & $47.19 \pm 1.72$ & $223.10 \pm 4.97$ & $46.08 \pm 0.17$ & $223.23 \pm 0.21$ \\
\hline IERS-NCEP(IB) & $1980 \ldots 1996$ & $51.76 \pm 2.16$ & $221.33 \pm 5.47$ & $49.80 \pm 0.16$ & $218.98 \pm 0.19$ \\
\hline JPL-NCEP(IB) & $1977 \ldots 1996$ & $53.64 \pm 2.31$ & $219.01 \pm 2.88$ & $52.84 \pm 0.18$ & $217.90 \pm 0.20$ \\
\hline \multicolumn{6}{|c|}{ For a transfer between the $L O D_{a t m}$ systems } \\
\hline NCEP-NMC(P) & $1982 \ldots 1994$ & & & $29.37 \pm 0.22$ & $263.43 \pm 0.43$ \\
\hline NCEP-NMC(IB) & $1982 \ldots 1994$ & & & $29.04 \pm 0.20$ & $267.85 \pm 0.39$ \\
\hline NCEP-JMA(P) & $1984 \ldots 1996$ & & & $5.63 \pm 0.17$ & $341.14 \pm 1.72$ \\
\hline NCEP-JMA(IB) & $1984 \ldots 1996$ & & & $5.90 \pm 0.16$ & $349.49 \pm 1.58$ \\
\hline IB(NCEP) & $1969 \ldots 1996$ & & & $2.32 \pm 0.10$ & $130.87 \pm 2.39$ \\
\hline IB(JMA) & $1984 \ldots 1996$ & & & $4.93 \pm 0.15$ & $67.06 \pm 1.72$ \\
\hline
\end{tabular}

Figure 1 represents the amplitude and phase estimates of the annual LOD- $L O D_{a t m}(1000-10)$ residual time series in the different systems as vectors. The same is shown in Fig. 2, but for the semiannual LOD-LOD atm $(1000-10)$ residual time series. Also indicated are the vectors for a transfer between the different $L O D_{a t m}$ systems. For the LOD$L O D_{a t m}(1000-10)$ and $L O D_{a t m}-L O D_{a t m}$ systems, the vectors are plotted and in particular those for estimates referred to (P) by solid arrows and those referred to (IB) by dashed arrows.

To assess the seasonal LOD- $L O D_{a t m}(1000-10)$ residual time series in the different systems, we compare their amplitude and phase estimates, in particular these given in Table 1a and shown as vectors in Fig. 1 at the annual frequency and those given in Table $1 \mathrm{~b}$ and shown as vectors in Fig. 2 at the semiannual frequency. Referred to the LOD systems, namely to the IERS and JPL systems, see that the results agree with each other rather well, for example those in the IERS-JMA(P) and JPL-JMA(P) systems. At the annual frequency, it should be noted that the magnitude for the IERS system is systematically a little larger than that for the JPL system. At the semiannual frequency, however, the amplitude estimates differ only within their uncertainties. Concerning the phase, we can say that, compared to the calculated standard deviations, the estimates are similar. 
Publication: Scientific Technical Report

No.: STR00/05

Author: J. Höpfner

Table 2. AAM and OAM data used. MJD is the Modified Julian Date

\begin{tabular}{lcc}
\hline Time series & \multicolumn{1}{c}{$\begin{array}{c}\text { Time interval } \\
\text { (calendar days) }\end{array}$} & $\begin{array}{c}\text { Time interval } \\
(\text { MJD) }\end{array}$ \\
\hline AAM UKMO UARS & Oct. 17, 1991... Nov. 28, 1997 & $48546.0 \ldots 50780.0$ \\
OAM ECHAM3 & Jan. 1, 1975 ... Dec. 31, 1994 & $42413.0 \ldots 49717.0$ \\
OAM MICOM & Feb. 17, 1992...Dec. 15, 1994 & $48669.0 \ldots 49701.0$ \\
\hline
\end{tabular}

In judging the results relating to the $L O D_{a t m}$ systems, i. e., to the JMA, NMC and NCEP systems, some points to note are as follows: Considering the appropriate vectors, in particular both for the wind plus pressure term without IB response $\chi_{3}(\mathrm{~W})+\chi_{3}(\mathrm{P})$ and for the wind plus pressure term with IB response $\chi_{3}(\mathrm{~W})+\chi_{3}(\mathrm{P}+\mathrm{IB})$, there are different phases at the annual frequency, but similar phases at the semiannual frequency. Except for the NMC system, the magnitudes of the vectors are similar to each other for both frequencies. Concerning the vectors for a transfer between the $L O D$ atm systems including the IB response, the annual magnitudes are clearly larger than the semiannual ones. By their directions, it is obviously confirmed that the results which are connected with each other in the $L O D_{a t m}$ systems match. Compared the role of the IB response in the JMA and NCEP systems, similar effects exist at the annual and semiannual frequencies, respectively. The annual effects, however, are about an order of magnitude larger than the semiannual ones. In Section 4 , we describe and discuss the AAM and OAM data sets used in this study and their processing including the results.

\section{Data sets used in this study, data processing and results}

The objective is to estimate the optimal amplitude and phase values of the terms $L O D_{\text {atm }}(10-0.3)$ and $L O D_{\text {ocean }}$ for the equation (4) at seasonal time scales.

Concerning $L O D_{a t m}(10-0.3)$, i. e., the contribution for the wind term from the atmospheric layer between the 10 and $0.3 \mathrm{hPa}$ levels to LOD changes, the atmospheric data sets used here are the AAM data for the 10-0.3 hPa layer derived from the U. K. Meteorological Office (UKMO) Upper Atmosphere Research Satellite (UARS) project. They are made available by D. A. Salstein and P. Nelson (private communication, 1999). Given in units of $\mathrm{kg} \mathrm{m}^{2} s^{-1}$, they are multiplied with the scale factor of $1.68 \times 10^{-29}$ and are thus expressed in seconds of time (s) like the LOD data. Details on the relationship between AAM and LOD can be found in, for example, Rosen (1993). For the time interval of the AAM data referred to UKMO UARS, see Table 2.

For the term $L O D_{\text {ocean }}$, i. e., the oceanic contribution to LOD changes, the oceanic data sets used here are the OAM data resulting from two global oceanic GCMs and in particular referred to as ECHAM3 and MICOM models. Concerning ECHAM3, the time series of the inertia tensor and of the relative angular momentum of the Oceans are made available by M. Thomas (private communication, 1999) and, concerning MICOM, that of OAM by S. L. Marcus (private communication, 1999). Considering the changes in the polar moment of inertia $c_{33}$ caused by changes in distribution of mass, i. e., the mass contribution, and the relative angular momentum $h_{3}$ caused by the changes in east-west oceanic currents, i. e., the motion contribution, we computed the axial OAM changes in the ECHAM system according to the formula (see e. g. Desai and Wahr 1992)

$\chi_{3}=\frac{0.756 \Omega c_{33}+h_{3}}{C_{m} \Omega}$

where $C_{m}$ is the polar moment of inertia of the Earth's mantle, and $\Omega$ the Earth's mean rotation rate. By inverting their signs and multiplying them with the scale factor of $8.64 \times 10^{4}$, the OAM values are converted into $L O D_{\text {ocean }}$ values. Again see Table 2, for the time intervals of the OAM time series relating to the ECHAM3 and MICOM systems.

Table 3. Time intervals for the annual and semiannual oscillations for the $L O D_{a t m}(10-0.3)$ and $L O D_{o c e a n}$ time series given in calendar days and MJD. MJD is the Modified Julian Date

\begin{tabular}{|c|c|c|}
\hline Time series / system & Annual oscillation & Semiannual oscillation \\
\hline AAM UKMO UARS & $\begin{array}{c}\text { Dec. } 19,1993 \ldots \text { Sept. } 26,1995 \\
49340.0 \ldots 49986.0\end{array}$ & $\begin{array}{c}\text { Nov. } 13,1992 \ldots \text { Oct. } 31,1996 \\
48939.0 \ldots 50387.0\end{array}$ \\
\hline OAM ECHAM3 & $\begin{array}{c}\text { March 5, } 1977 \text {... Oct. 28, } 1992 \\
43207.0 \ldots 48923.0\end{array}$ & $\begin{array}{c}\text { Jan. } 29,1976 \ldots \text { Dec. } 3,1993 \\
42806.0 \ldots 49324.0\end{array}$ \\
\hline OAM MICOM & $\begin{array}{c}\text { April 3, } 1993 \ldots \text { Oct. } 30,1993 \\
49080.0 \ldots 49290.0\end{array}$ & $\begin{array}{c}\text { Sept. 9, } 1992 \ldots \text { May 24, } 1994 \\
48874.0 \ldots 49496.0\end{array}$ \\
\hline
\end{tabular}


Publication: Scientific Technical Report

No.: STR00/05

Author: J. Höpfner

SERIES AAM UKMO UARS 1991-1997
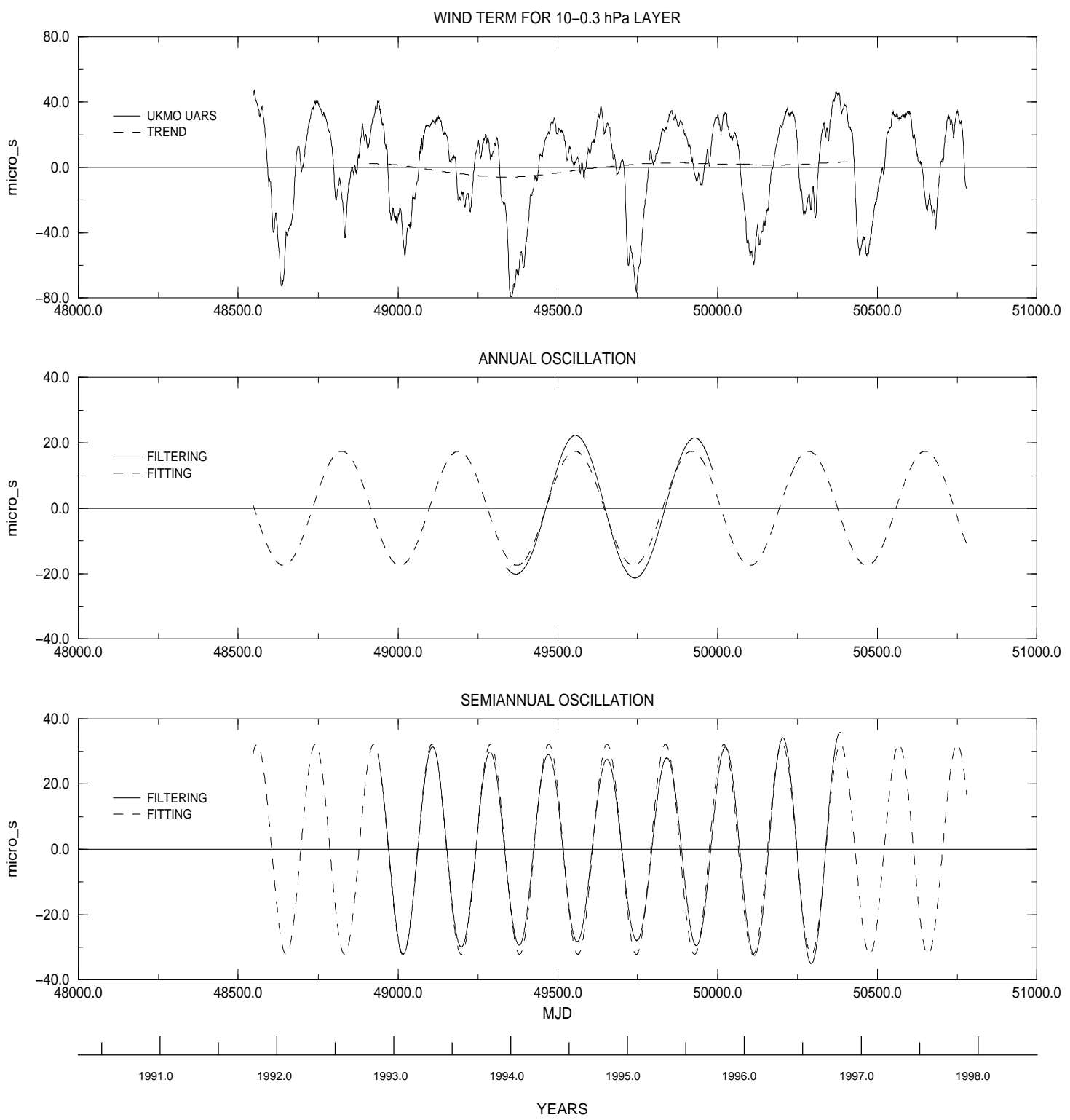

Figure 3. $L O D_{a t m}(10-0.3)$ variations, i. e., LOD variations as inferred by AAM for the 10-0.3 hPa layer between 1991 and 1997 (top) and their oscillations at the annual frequency (centre) and at the semiannual frequency (bottom). Note that each oscillation is shown as component obtained from both filtering and least-square fitting 
Publication: Scientific Technical Report

No.: STR00/05

Author: J. Höpfner

SERIES OAM ECHAM3 1977-1992
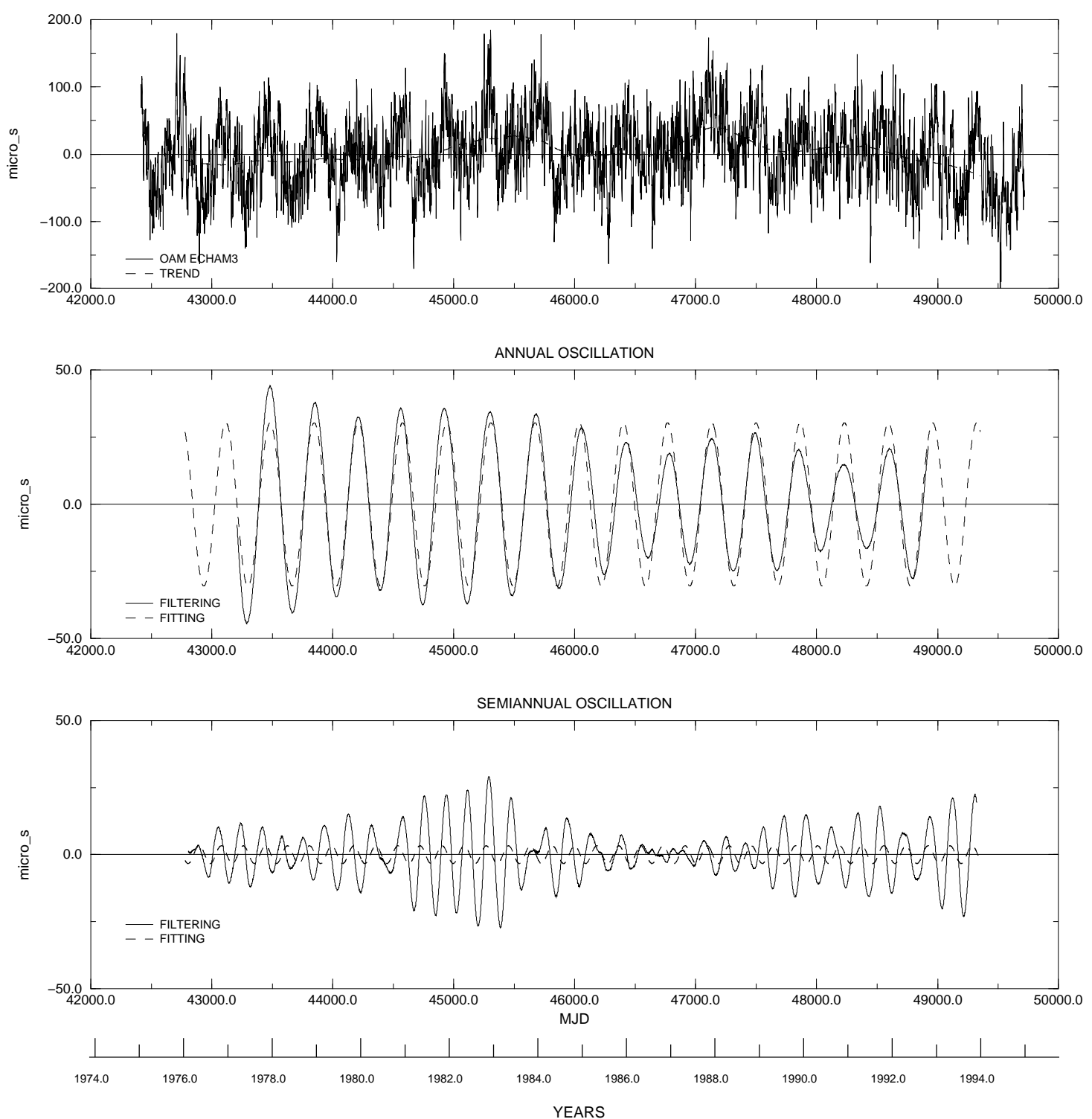

Figure 4. $L O D_{\text {ocean }}$ variations, i. e., LOD variations as inferred by OAM ECHAM3 between 1975 and 1994 (top) and their oscillations at the annual frequency (centre) and at the semiannual frequency (bottom). Note that each oscillation is shown as component obtained from both filtering and least-square fitting 
Publication: Scientific Technical Report

No.: STR00/05

Author: J. Höpfner

SERIES OAM MICOM 1992-1994
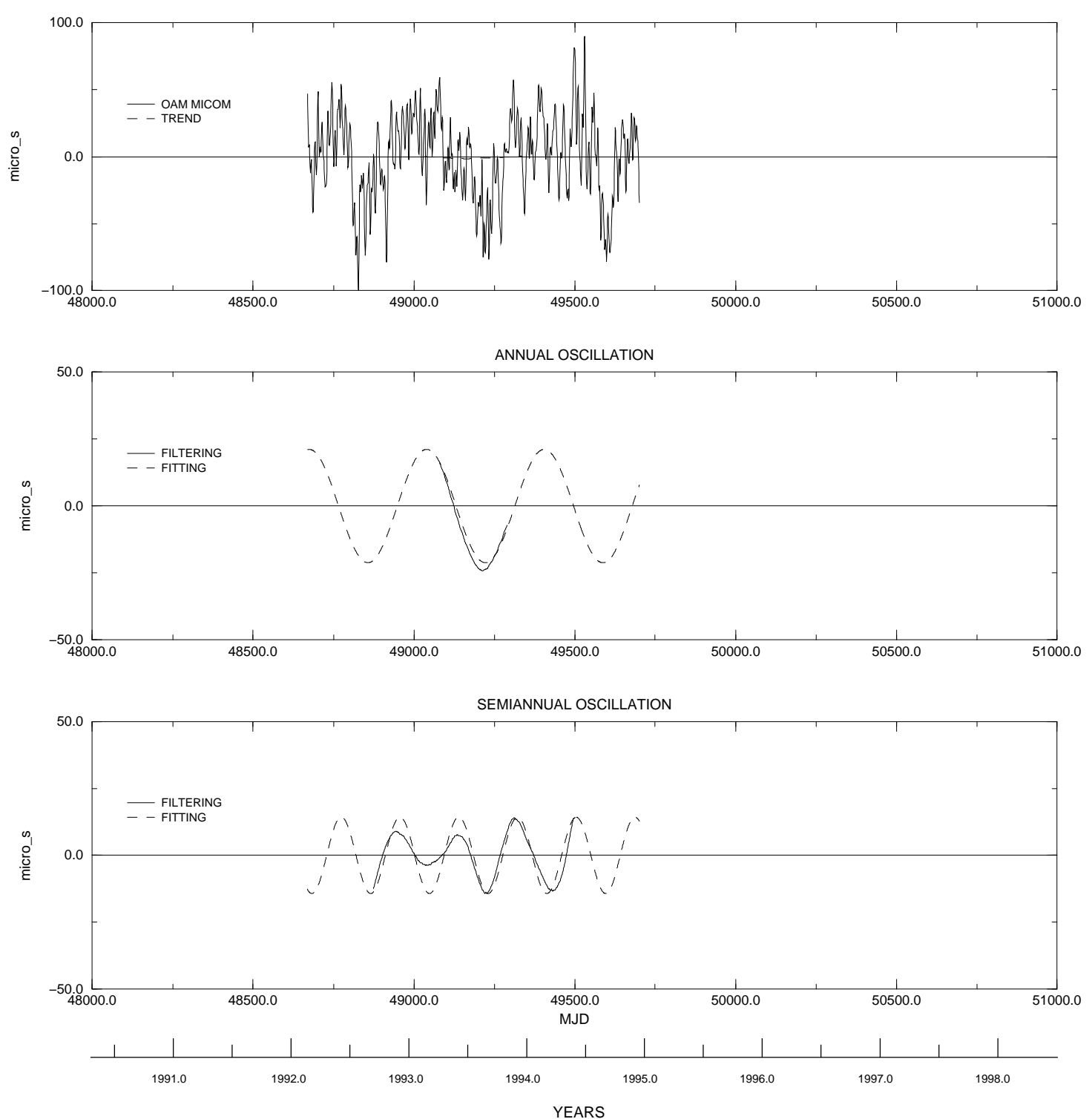

Figure 5. $L O D_{o c e a n}$ variations, i. e., LOD variations as inferred by OAM MICOM between 1992 and 1994 (top) and their oscillations at the annual frequency (centre) and at the semiannual frequency (bottom). Note that each oscillation is shown as component obtained from both filtering and least-square fitting 
Publication: Scientific Technical Report

No.: STR00/05

Author: J. Höpfner

Table 4. Amplitude and phase estimates including the standard deviations of the seasonal oscillations for the $L O D_{a t m}(10-0.3)$ and $L O D_{o c e a n}$ time series. The phase angle with respect to the cosine convention refers to January 1 . Units are: Amplitude values in $\mu$ s, phase values in degrees

\begin{tabular}{lccccc}
\hline Time series / system & Time interval & \multicolumn{2}{l}{ Results from our method } & \multicolumn{2}{l}{ Results from fit } \\
& & Amplitude & Phase & Amplitude & Phase \\
\hline (a) Annual oscillation & & & & & \\
AAM UKMO UARS & $1993 \ldots 1995$ & $21.34 \pm 0.78$ & $197.19 \pm 1.63$ & $17.47 \pm 0.36$ & $198.74 \pm 1.18$ \\
OAM ECHAM3 & $1977 \ldots 1992$ & $29.23 \pm 1.34$ & $330.92 \pm 4.33$ & $30.43 \pm 0.76$ & $332.17 \pm 1.43$ \\
OAM MICOM & $1993 \ldots 1993$ & $24.23 \pm 1.10$ & 353.92 & $21.16 \pm 1.10$ & $51.67 \pm 3.00$ \\
& & & & & \\
(b) Semiannual oscillation & & & & & \\
AAM UKMO UARS & $1992 \ldots 1997$ & $30.70 \pm 0.49$ & $239.24 \pm 1.57$ & $32.15 \pm 0.36$ & $235.00 \pm 0.64$ \\
OAM ECHAM3 & $1976 \ldots 1993$ & $12.73 \pm 1.62$ & & $3.30 \pm 0.76$ & $229.23 \pm 13.18$ \\
OAM MICOM & $1992 \ldots 1994$ & $10.34 \pm 2.41$ & $286.67 \pm 4.24$ & $14.26 \pm 1.10$ & $300.10 \pm 4.44$ \\
\hline
\end{tabular}

For generating the OAM data, or the corresponding $L O D_{\text {ocean }}$ data, some comments on the oceanic GCMs should be noted:

(a) OAM results in the ECHAM3 system

As described by Thomas and Sündermann (1998, 2000), the Ocean Model for Circulation and Tides developed at the Zentrum für Meeres-und Klimaforschung (ZMK) of the University Hamburg is based on non-linear balance equations of momentum conservation, the continuity equation for an incompressible fluid, and conservation equations for heat and salt using the hydrostatic and Boussinesq approximations. Sea ice is simulated by a Hibler model. Concerning the configuration, it has a horizontal resolution of $1.875^{\circ}$ in longitude and latitude and 13 layers in the vertical. To simulate the Ocean's general circulation, the model is driven with atmospheric forcing fields from simulations of the atmospheric general circulation model ECHAM3 including wind stresses, surface temperatures, freshwater fluxes, and mean sea level pressure.

(b) OAM results in the MICOM system

As described by Marcus et al. (1998), MICOM stands for Miami Isopycnic-Coordinate Ocean Model. It is based on the primitive equations of fluid flow that use the hydrostatic and Boussinesq approximations. Concerning the configuration, it has a horizontal resolution of $2^{\circ}$ longitude by $1^{\circ}$ latitude and 11 vertical layers with a mixed layer and a free surface. To simulate the global oceanic general circulation, the model is driven with surface wind stress and heat flux computed from daily NCEP analyses. Here, pressure forcing by the atmosphere is not considered.

In each system, the OAM time series contains the non-tidal oceanic contribution, including matter and current terms, to LOD changes.

To separate the seasonal oscillations from the $L O D_{\text {atm }}(10-0.3)$ and $L O D_{\text {ocean }}$ time series, we applied two zero-phase digital band-pass filters designed by Höpfner (1996) to the available data sets made as in our previous studies (Höpfner 1996, 1997, 1998a, b, 2000). Using the low-pass filter, we filtered out the low-frequency component from the time series of $L O D_{\text {atm }}(10-0.3)$ and those of $L O D_{\text {ocean }}$ in both systems for information and check, respectively.. For the time intervals of the time series of the annual and semiannual oscillations filtered out from the $L O D_{a t m}(10-0.3)$ and $L O D_{\text {ocean }}$ time series, see Table 3 . Note that the filtered series are truncated at the beginning and the end of the analysis intervals.

Figures 3 to 5 present the $L O D_{a t m}(10-0.3)$ and $L O D_{\text {ocean }}$ variations, their low-frequency components and their seasonal oscillations, with the top panel showing the variation with its low-frequency component, the middle panel the annual component and the bottom panel the semiannual component. In particular, the curves in Fig. 3 refer to the $L O D_{a t m}(10-0.3)$ and those in Figs. 4 and 5 to $L O D_{\text {ocean }}$ in the ECHAM3 and MICOM systems, respectively. In each top panel, the low-frequency component of the variation, referred to as trend, is plotted by a dashed line. For the $L O D_{a t m}(10-0.3)$ variations, the low-frequency component is rather small. The $L O D_{\text {ocean }}$ variations in the ECHAM3 system are characterized by a low-frequency component changing with time considerably. In contrast, the LOD variations inferred by OAM in the MICOM system should show no low-frequency component. As submitted by S. L. Marcus (private communication, 1999), a mean, linear trend, and quadratic term have been already removed from the series. 
Table 5. Amplitude and phase estimates of the seasonal signals for the term $L O D_{h y d r o l}$. The phase angle with respect to the cosine convention refers to January 1. Units are: Amplitude values in ms, phase values in degrees. For comparison, the estimates of the contribution for the wind term from the 10-1 hPa layer and for the Antarctic Circum-Polar Current (ACPC) are added as further entries

\begin{tabular}{|c|c|c|c|c|}
\hline Contribution & Time interval & Amplitude & Phase & Source \\
\hline \multicolumn{5}{|c|}{ (a) Annual signal } \\
\hline Rain & & 0.0090 & 327.0 & Willmot, Rowe and Mintz(1985) \\
\hline Snow & $1979 \ldots 1985$ & 0.0204 & 48.0 & Chao et al. (1987) \\
\hline Total: Water & & 0.0237 & 26.0 & Chao and O'Connor (1988) \\
\hline Wind (10-1) & $1980 \ldots 1985$ & 0.025 & 212.2 & Höpfner $(1997,1998 b)$ \\
\hline ACPC & $1977 \ldots 1982$ & 0.003 & 311.4 & Whitworth and Peterson (1985) \\
\hline \multicolumn{5}{|c|}{ (b) Semiannual signal } \\
\hline Rain & & 0.0080 & 208.0 & Willmot, Rowe and Mintz(1985) \\
\hline Snow & $1979 \ldots 1985$ & 0.0044 & 117.0 & Chao et al. (1987) \\
\hline Total: Water & & 0.0090 & 178.0 & Chao and O'Connor (1988) \\
\hline Wind (10-1) & $1980 \ldots 1985$ & 0.028 & 255.3 & Höpfner (1997, 1998b) \\
\hline $\mathrm{ACPC}$ & & 0.005 & 200.1 & Whitworth and Peterson (1985) \\
\hline
\end{tabular}

As can be seen in Fig. 3, both seasonal $L O D_{a t m}$ (10-0.3) oscillations vary in amplitude only a little with time, by about $5 \mu \mathrm{s}$ at the annual frequency, and by about $10 \mu \mathrm{s}$ at the semiannual frequency. In case of the $L O D_{\text {ocean }}$ oscillations for the ECHAM3 system shown in Fig. 4, however, we notice significant amplitude changes. Here, the annual oscillation has an amplitude of 15 to $55 \mu \mathrm{s}$, and the semiannual one an amplitude of 5 to $30 \mu \mathrm{s}$. If comparing the seasonal $L O D_{\text {ocean }}$ oscillations in the ECHAM3 system with those in the MICOM system shown in Fig. 5, note that the curves should be similar to each other to reflect significant signals, whereas disagreements may be due to systematic differences between the $L O D_{\text {ocean }}$ systems. Since the OAM time series in the MICOM system is only two years long, we decided to use seasonal band-pass filters having a cosine shape modified over two periods as weight function. At the annual frequency, there is no common results, and, at the semiannual frequency, the common interval is relatively short. Assessing the $L O D_{\text {ocean }}$ results in both systems, we can say that the amplitudes of the annual oscillations are of similar magnitude. On the contrary, the semiannual oscillation in the ECHAM3 system is significantly larger in amplitude than that in the MICOM system over the common interval.

In the same manner to the seasonal residual time series for the different LOD- $L O D_{a t m}(1000-10)$ systems, the seasonal oscillations for the $L O D_{a t m}(10-0.3)$ and $L O D_{\text {ocean }}$ time series are processed to obtain amplitude and phase estimates and their standard deviations; for it, see Section 3. Analogous to the results given in Table 1, the amplitude and phase estimates including the standard deviations of the seasonal oscillations for the $L O D_{\text {atm }}(10-0.3)$ and $L O D_{\text {ocean }}$ time series are compiled in Table 4. For the representation of the results as vectors, see Figs. 6 and 7 in Section 5. There, we shall judge them together with other results.

Concerning equation (4), we still need the seasonal amplitude and phase estimates of the term $L O D_{\text {hydrol }}$. However, as already mentioned in Section 1 , no $L O D_{h y d r o l}$ time series was available for estimating the hydrological contributions to LOD changes. Therefore, we use the contributions from the surface water storage estimated by Chao and O'Connor (1988). For the amplitude and phase estimates of the seasonal signals for the term $L O D_{\text {hydrol }}$, see Table 5. Here, Rain designates the contribution of rainfall and evapotranspiration, Snow the snow contribution and Water their sum, i. e., the total contribution for the continental surface water storage. For purposes of comparison, the estimates of the contribution for the wind term from the 10-1 hPa layer and for the Antarctic Circum-Polar Current (ACPC) are also listed. Note that there are no uncertainties for the estimates. Again see Figs. 6 and 7 for their vector representation.

In Section 5, at the seasonal time scales, we shall show and discuss the atmospheric, oceanic and hydrological contributions to LOD changes and assess the global axial angular momentum budget with respect to its balance using the vector representation.

\section{Global axial angular momentum budget on the seasonal time scales}

Our considerations relating to the global axial angular momentum budget on the seasonal time scales are based on equation (4) given in Section 2. As for the seasonal discrepancies in the solid Earth-atmosphere axial angular momentum budget shown in Figs. 1 and 2 of Section 3, we use vectors to illustrate the atmospheric, oceanic and hydrological contributions to LOD changes and to discuss the extent to what a closed budget is achieved within the estimated uncertainties in all momentum quantities. 
Publication: Scientific Technical Report

No.: STR00/05

Author: J. Höpfner

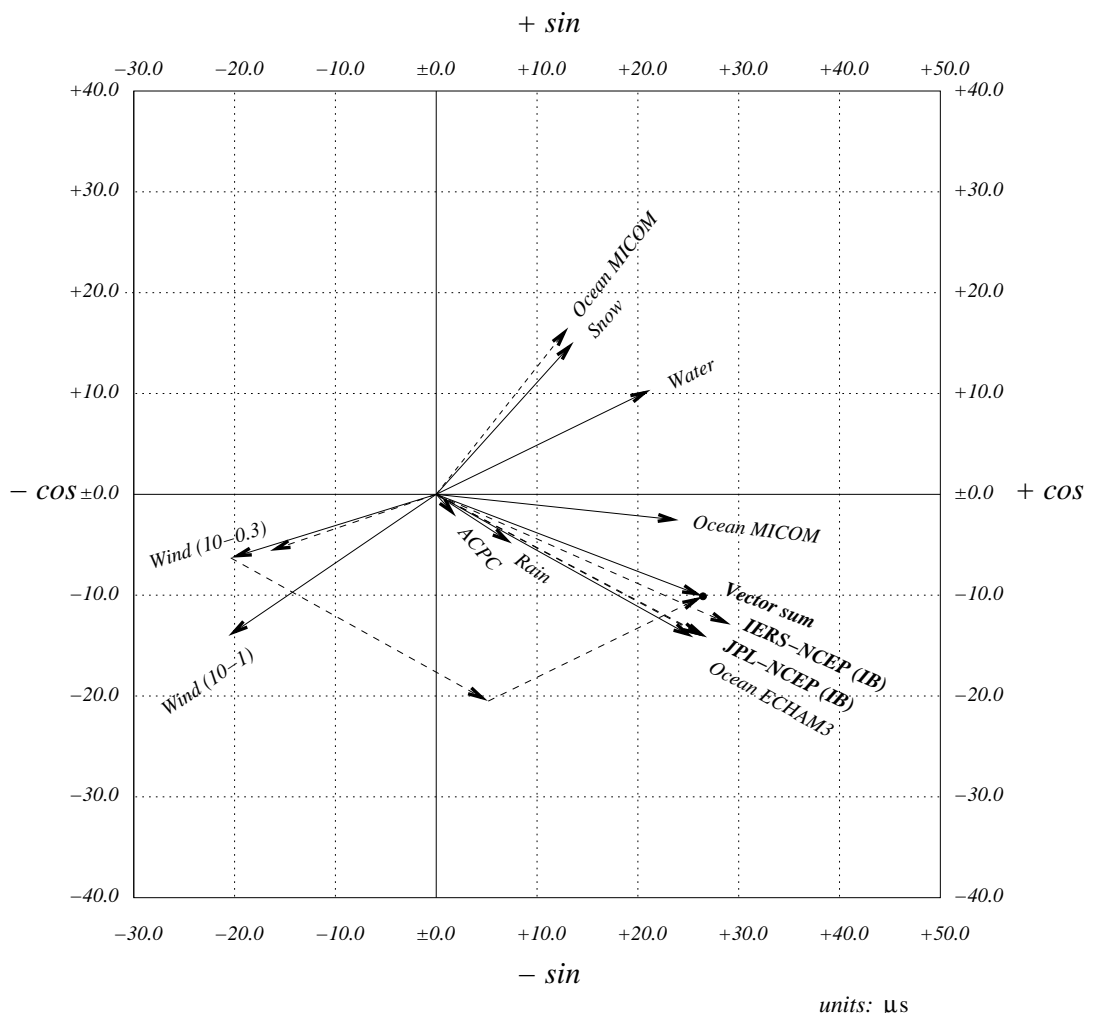

Figure 6. Vector representation of the amplitude and phase estimates of the annual $L O D_{a t m}(10-0.3)$ and $L O D_{\text {ocean }}$ oscillations. The water storage vector estimate, referred to as the Water, for the term $L O D_{h y d r o l}$ is also shown, where the Water vector is the sum of the Rain and Snow vectors. The Vector sum formed from the vectors for the terms $L O D_{a t m}(10-0.3), L O D_{\text {ocean }}$ and $L O D_{h y d r o l}$ should be compared with the vector for the annual LOD- $L O D_{a t m}(1000-10)$ residual time series in the IERS-NCEP(IB) and JPL-NCEP(IB) systems, respectively. Also displayed, for comparison, are the vectors of the contribution for Wind(10-1) and ACPC

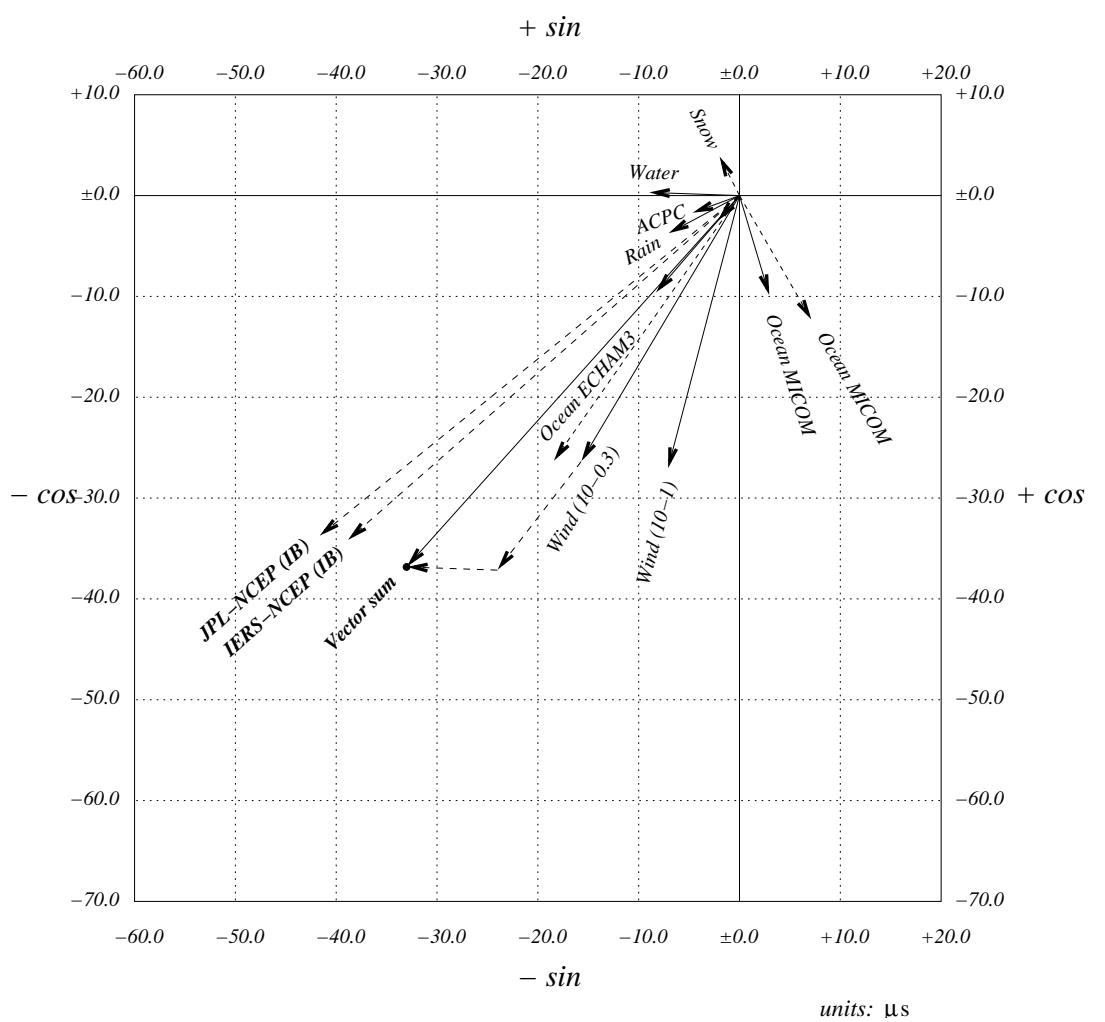

Figure 7. As for Fig. 6, but for the semiannual $L O D_{a t m}(10-0.3)$ and $L O D_{o c e a n}$ oscillations 
Publication: Scientific Technical Report

No.: STR00/05

Author: J. Höpfner

Table 6. Final results: Amplitude and phase estimates and their standard deviations of the seasonal signals for the terms $\left\{L O D-L O D_{a t m}(1000-10)\right\}$ and $L O D_{a t m}(10-0.3)+L O D_{o c e a n}+L O D_{h y d r o l}$, i. e., left-hand and right-hand sides of equation (4), respectively. The phase angle with respect to the cosine convention refers to January 1. Units are: Amplitude values in $\mu$ s, phase values in degrees

\begin{tabular}{|c|c|c|c|c|}
\hline Term & System & Amplitude & Phase & Source \\
\hline \multicolumn{5}{|l|}{ (a) Annual signal } \\
\hline \multirow[t]{2}{*}{ LOD - LOD } & IERS-NCEP(IB) & $31.99 \pm 3.39$ & $336.14 \pm 0.36$ & Table 1 \\
\hline & JPL-NCEP(IB) & $30.02 \pm 3.03$ & $331.98 \pm 6.39$ & \\
\hline$L O D_{a t m}(10-0.3)+$ & Vector sum & $28.33 \pm 4.47$ & $339.06 \pm 4.88$ & Table 4; \\
\hline$L O D_{\text {ocean }}+L O D_{\text {hydrol }}$ & & & & Table 5 \\
\hline \multicolumn{5}{|l|}{ (b) Semiannual signal } \\
\hline \multirow[t]{2}{*}{ LOD - LOD $D_{a t m}(1000-10)$} & IERS-NCEP(IB) & $51.76 \pm 2.16$ & $221.33 \pm 5.47$ & Table 1 \\
\hline & JPL-NCEP(IB) & $53.64 \pm 2.31$ & $219.01 \pm 2.88$ & \\
\hline$L O D_{a t m}(10-0.3)+$ & Vector sum & $48.63 \pm 3.70$ & $227.25 \pm 4.64$ & Table 4; \\
\hline$L O D_{\text {ocean }}+L O D_{\text {hydrol }}$ & & & & Table 5 \\
\hline
\end{tabular}

Figure 6 shows the amplitude and phase estimates of the $L O D_{\text {atm }}(10-0.3)$ and $L O D_{\text {ocean }}$ terms as vectors at the annual frequency, and Fig. 7 the same but at the semiannual frequency. As in Figs. 1 and 2, the vectors are displayed, with the estimates derived from our method plotted by solid arrows and those from least-square fit by dashed arrows. For comparison, in each figure, the vectors for further contributions are indicated. In particular, the following notations are used: Wind(10-0.3) stands for the $L O D_{\text {atm }}(10-0.3)$ term in the UKMO UARS system given in Table 4, and Wind(10-1) for the wind term from the 10-1 hPa layer according to Höpfner $(1997,1998 b)$ given in Table 5. For the $L O D_{\text {ocean }}$ term, we have the oceanic estimates from the ECHAM3 and MICOM simulations (see Table 4). They are referred to as Ocean ECHAM3 and Ocean MICOM, respectively. ACPC is the contribution for the Antarctic Circum-Polar Current according to Whitworth and Peterson (1985); see Table 5 for its estimates. As noted in Section 4, for the $L O D_{h y d r o l}$ term, Water, incorporating Rain and Snow, used here are the hydrological influences according to Chao and O'Connor (1988). Again see Table 5 for their estimates. For the LOD- $L O D_{a t m}(1000-10)$ term, the amplitude and phase estimates of the seasonal oscillations in different systems are presented in Table 1. However, compared to Figs. 1 and 2, the vector of the IERSNCEP(IB) and JPL-NCEP(IB) systems are only shown in Figs. 6 and 7.

The following discussion will be separately on the contributions to LOD changes at the annual and semiannual frequencies. Here, in assessing the estimates obtained from the two methods cited in Section 3 , we particularly refer to those from our method.

(a) Contributions to LOD changes at the annual frequency

In Fig. 6, we see that the Wind(10-0.3) and Wind(10-1) vectors are rather similar in amplitude. But, the Wind(10$0.3)$ phase is smaller than that of Wind(10-1) by 15 degrees. Considering that the wind contributions refer to the top level of the atmosphere of 0.3 and $1 \mathrm{hPa}$, respectively, it is confirmed that the estimates are in keeping with each other, i.e. realistic. Comparing the Ocean ECHAM3 and Ocean MICOM vectors, note that the amplitudes are of the same magnitude, whereas the phases differ by about 20 degrees, with the Ocean ECHAM3 phase smaller than that of Ocean MICOM. Consequently, the oceanic contributions for both systems differ significantly in phase. Since the phase of the ACPC vector is closer to that of the Ocean ECHAM3 vector than to that of the Ocean MICOM vector, we regard the Ocean ECHAM3 estimates as the better ones. As described by Chen et al. (1997), the hydrological contribution to LOD changes was derived by using the NCEP-NCAR Climate Data Assimilation System I (CDAS-1) from soil moisture and snow fields from 1974 to 1995 . In particular, the $L O D_{h y d r o l}$ variations, i. e., the LOD variations as inferred by HAM CDAS-1 between 1985 and 1995, can be found in terms of a curve in Chen et al. (1997), where a clear annual signal exists. Compared to the Water contribution plotted as vector in Fig. 6, the amplitude of the contribution in the CDAS-1 system is much larger but its phase is consistent to our estimate. Notice that the vectors for Wind(10-0.3) and Water are similar in magnitude but opposite in direction. 
(b) Contributions to LOD changes at the semiannual frequency

In Fig. 7, note that the amplitude of Wind(10-0.3) vector agrees well with that of Wind(10-1). In case of the phase, there exists a significant difference of about 15 degrees in the same sense as for the annual wind vectors. Again as in (a), being considered the difference in the systems due to the different top levels, we can say that the estimates are conformable. Concerning the Ocean ECHAM3 and Ocean MICOM vectors, notice the same facts as found at the annual frequency, i. e., there is good agreement between the amplitude estimates, but a significant difference between the phase estimates having about 60 degrees. Like to the annual Ocean ECHAM3 and Ocean MICOM vectors, with closer phase of the ACPC vector to that of Ocean ECHAM3 vector, we note the same at the semiannual frequency. This result confirms our assessment relating to the more realistic oceanic model as given in (a). Concerning the Water contribution plotted as vector in Fig. 7, unlike to (a), it is impossible to make a comparison to the $L O D_{\text {hydrol }}$ variations in the CDAS- 1 system derived by Chen et al. (2000). The reason is that the semiannual signal is not discernible on the scale used for the y-axis. Also, there is no similarity to the Wind(10-0.3) vector.

At the annual and semiannual frequencies, comparing the oceanic signals in the POCM-4B system (POCM stands for Parallel Ocean Climate Model) estimated by Johnson et al. (1999) with those in the ECHAM3 system, we find that the amplitudes for POCM-4B are significantly smaller, and the phases with respect to the cosine convention as well. Concerning the $L O D_{\text {ocean }}$ term, Chen et al. (1997) applied to sea level variations from TOPEX/POSEIDON (T/P) altimeter data after removing steric effect. For a comparison between those and the oceanic contributions in the ECHAM3 system, using least-square fit, we computed the annual and semiannual Fourier components of the T/P data made available by J. L. Chen (private communication, 2000). Note that our estimates for the ECHAM3 system are significantly smaller in annual amplitude but larger in semiannual amplitude than those for T/P with steric correction, and there is disagreement in phase.

Finally, for the terms $L O D_{a t m}(10-0.3), L O D_{\text {ocean }}$ and $L O D_{\text {hydrol }}$, Figs. 6 and 7 show the Vector sums, each formed from the corresponding vectors of Wind(10-0.3), Ocean ECHAM3 and Water; for the amplitude and phase estimates, see Table 6. To compute their standard deviations according to the law of the propagation of errors, for the seasonal Water contributions given in Table 5, we used $\pm 5 \mu \mathrm{s}$ in amplitude and \pm 15 degrees in phase as estimated errors. According to equation (4), the Vector sums should be compared with the vectors for the LOD-LOD atm $(1000-10)$ term, in particular with the IERS-NCEP(IB) and JPL-NCEP(IB) vectors displayed in these figures. As we can see, at both the annual and semiannual frequencies within the estimated uncertainties, the amplitudes of the two cited vectors have the same magnitude as that of the Vector sum. Likewise for their phases, note that, considering the phases of the IERS-NCEP(IB) and JPL-NCEP(IB) vectors, there are good agreement to the phase of the Vector sums. Compared with all the LOD- $L O D_{a t m}(1000-10)$ vectors shown in Figs. 1 and 2, respectively, it should be remarked that, in case of the annual frequency, only the IERS-NCEP(IB) and JPL-NCEP(IB) vectors have such a direction as wanted, but, in case of the semiannual frequency, further vectors are similar in magnitude and direction, namely those of IERS-JMA(IB) and JPL-JMA(IB). Moreover, since the difference between the $L O D_{a t m}$ systems with and without IB response is rather small in magnitude, the same applies to the semiannual vectors of the four LOD- $L O D_{a t m}(1000-10)$ systems as cited above but without IB response, i. e., designated with (P) instead of (IB).

In assessing our final results summarized in Table 6 , we can say that, by using vector representation and operation, a close balance in the global axial angular momentum budget is achieved within the estimated uncertainties of the momentum quantities in magnitude and within the differences between two LOD- $L O D_{a t m}(1000-10)$ estimates in direction at both annual and semiannual frequencies.

\section{Summary and concluding remarks}

Seasonal imbalances in the solid Earth-atmosphere axial angular momentum budget in terms of the annual and semiannual residuals calculated as time series in different LOD- $L O D_{a t m}$ systems reflected significant signals. In the complex Earth system including solid Earth, atmosphere, oceans, hydrosphere, liquid core, and geophysical fluids such as the melting of glaciers, sea level rise, and post-glacial rebound, they may be caused by further excitation sources. Therefore, the present study focuses on other contributions to LOD changes at seasonal time scales.

Our considerations refer to the atmospheric, oceanic and hydrological excitations, strictly speaking, the contributions to LOD inferred from AAM, OAM, and HAM, and are based on equation (4), showing the term $\left\{\right.$ LOD- $\left.L O D_{a t m}(1000-10)\right\}$ in the left-hand-side and the terms $L O D_{a t m}(10-0.3), L O D_{\text {ocean }}$, and $L O D_{\text {hydrol }}$ in the right-hand-side. To realize vector representation and operation, the amplitude and phase estimates or their Fourier coefficients have to be derived from the seasonal time series for the different terms. 
Preparatory to this, the residual oscillations for the LOD- $L O D_{a t m}(1000-10)$ term from our previous studies (Höpfner 1996, 1997, 1998a, b, 2000) are processed by means of both methods, and in particular that of parameter estimating as described in Höpfner (1997, 1998b) and that of least-square fitting. These results referred to the different LOD systems, and in particular of IERS and JPL, show good agreement in amplitude and phase with each other at both frequencies. In comparison, referred to the different $L O D_{a t m}$ systems, and in particular of JMA and NCEP without and with IB response, the following distinction exists: At the annual frequency, the amplitudes are similar but the phases different, whereas, at the semiannual frequency, both the amplitudes and phases are similar. Concerning the role of the IB response, note that the IB effects are similar in the JMA and NCEP systems, but with the annual ones being about an order of magnitude larger than the semiannual ones.

To estimate the amplitudes and phases of the seasonal oscillations concerning further contributions to LOD changes, the following time series are processed in this study:

(a) AAM UKMO UARS from 1991 to 1997 for the term $L O D_{\text {atm }}(10-0.3)$

(b) OAM ECHAM3 from 1975 to 1994 and OAM MICOM from 1992 to 1994 for the term $L O D_{\text {ocean }}$.

Here, we applied processing as in our previous studies, and, for comparison, least-square fitting the data. For the amplitude and phase estimates derived by the two methods, it should be noted that we particularly apply to the results from our method, since they appear more significant than those from the least-square fit.

For $L O D_{a t m}(10-0.3)$, the seasonal oscillations have relatively small amplitude changes. On the contrary, for $L O D_{\text {ocean }}$ in the ECHAM3 system, there exist significantly larger variations in amplitude with time at both frequencies. Compared the oscillations of both $L O D_{\text {ocean }}$ systems, at the annual frequency, their amplitudes are similar, while, at the semiannual frequency, the amplitudes of ECHAM3 are larger than those of MICOM.

For the $L O D_{\text {hydrol }}$ term, since no $L O D_{\text {hydrol }}$ time series was available, the amplitudes and phases of the seasonal signals for the contribution from the surface water storage estimated by Chao and O'Connor (1988) are used.

The annual amplitude and phase estimates for the $L O D_{a t m}(10-0.3), L O D_{o c e a n}$, and $L O D_{h y d r o l}$ terms are shown as vectors in Fig. 6, and the semiannual ones in Fig. 7. Also indicated are the vectors for the LOD-LOD atm $(1000-10)$ term in the IERS-NCEP(IB) and JPL-NCEP(IB) systems in both figures. These should be compared with the vector sum of equation (4), formed from the vectors for $L O D_{a t m}(10-0.3), L O D_{\text {ocean }}$, and $L O D_{h y d r o l}$.

Assessing the results based on intercomparisons, we can summarize our findings as follows.

(a) For the term $L O D_{a t m}(10-0.3)$, the contributions for the wind term from the atmospheric layer between the 10 and $0.3 \mathrm{hPa}$ levels as estimated at the seasonal frequencies are realistic. For the term $L O D_{\text {ocean }}$, the oceanic contributions estimated for the ECHAM3 and MICOM systems are similar in amplitude but significantly different in phase. Compared with the contributions for the Antarctic-Circum-Polar Current, there are the phases closer to those of ECHAM3. Therefore, we consider that the ECHAM3 estimates are the better ones, i. e., the oceanic model ECHAM3 is more realistic than the MICOM model. For the $L O D_{h y d r o l}$ term, note that the annual signal for the contribution from the surface water storage estimated by Chao and O'Connor (1988) and that for the hydrological contribution derived by using CDAS-1 from soil moisture and snow fields as described by Chen et al. (1997) is likely consistent in phase; however, the amplitude of CDAS-1 is much larger.

(b) Comparing the Vector sum, formed from the vectors of the $L O D_{a t m}(10-0.3), L O D_{o c e a n}$, and $L O D_{h y d r o l}$ terms, with the LOD-LOD atm (1000-10) vectors in the IERS-NCEP(IB) and JPL-NCEP(IB) systems at both the annual and semiannual frequencies, we find agreement in magnitude within the uncertainties estimated for the different terms and in direction within the differences for the LOD- $L O D_{a t m}(1000-10)$ systems. Table 6 shows the final results. Consequently, on the seasonal time scales, using amplitude and phase estimates derived over different intervals for vector operation according to equation (4), the global axial angular momentum budget is closed at the achieved level of uncertainty.

The following conclusions can be drawn. Further studies in this field should be aimed at refining the global axial angular momentum budget including all momentum quantities.

Concerning AAM, there are, for example, the large phase differences between the NCEP and JMA systems at the annual frequency. Moreover, the AAM time series for the 10-0.3 hPa layer of UKMO UARS is only available until 1997.

Previous studies using OAM data obtained with the oceanic GCMs of the various types show that significant discrepancies between the results exist. Apparently, the OAM time series in the ECHAM3 system is the longest one, and, at seasonal frequencies, the oceanic contributions estimated from this are reliable to a high degree. The contributions using sea level variations from T/P with steric correction are in disagreement. These discrepancies need investigating. 
Finally, concerning HAM, an area of special consideration is research to better understand and model the transportation of water between the oceans, atmosphere, and land. If HAM data are available for the $L O D_{h y d r o l}$ term, these could be processed in a similar manner as described here to estimate the optimal amplitude and phase values of the hydrological LOD contribution at the annual and semiannual frequencies.

Of important interest are high-resolution LOD, AAM, OAM, and HAM time series with a high level of accuracy over a common long time interval. In both the time and frequency domains, these would enable research leading to pronounced advances.

Acknowledgements. We are grateful to David A. Salstein and Peter Nelson, AER, Inc., Cambridge for providing the AAM data derived from the UKMO Upper Atmosphere Research Satellite project, Maik Thomas, ZMK, Hamburg for providing the oceanic data of the inertia tensor and of the relative angular momentum relating to the ECHAM3 model, Steven L. Marcus, JPL, Pasadena for providing the OAM data relating to the MICOM model, and Jianli L. Chen, University of Texas at Austin, for providing the TOPEX/POSEIDON data.

\section{References}

Barnes, R. T. H., Hide, R., White, A. A. and Wilson, C. A., 1983. Atmospheric angular momentum fluctuations, length-of-day changes and polar motion, Proc. Roy. Soc. Lond., A, 387, 31-73.

Chao, B. F. and O'Connor, W. P., 1988. Global surface-water-induced seasonal variations on the Earth's rotation and gravitational field. Geophys. J., 94, 263-270.

Chao, B. F., O'Connor, W. P., Chang, A. T. C., Hall, D. K. and Foster, J. L., 1987. Snow-load effect on the Earth's rotation and gravitational field, 1979-1985. J. Geophys. Res., 92, 9415-9422.

Chen, J. L., Wilson, C. R., Chao, B. F. and Shum, C. K., 1997. Hydrological and oceanic angular momentum and Earth rotation. Poster G31A-15. Fall Meeting of the AGU. San Francisco.

Desai, S. D. and Wahr, J. M., 1999. Monthly and fortnightly tidal variations of the Earth's rotation predicted by a TOPEX/POSEIDON empirical ocean tide model. Geophys. Res. Lett., 26, 8, 1035-1038.

Dickey, J. O., Marcus, S. L., Johns, C. M., Hide, R. and Thompson, S. R., 1993. The oceanic contribution to the Earth's seasonal angular momentum budget. Geophys. Res. Lett., 20, 24, 2953-2956.

Gaspar, P. and Ponte, R. M., 1997. Relation between sea level and barometric pressure determined from altimeter data and model simulations. J. Geophys. Res., 102, 961-971.

Hide, R. and Dickey, J. O., 1991. Earth's variable rotation. Science, 253, 629-637.

Höpfner, J., 1996. Seasonal oscillations in length-of-day, Astron. Nachr., 317, 273-280.

Höpfner, J., 1997. Seasonal variations in length-of-day and atmospheric-angular-momentum, Scientific Technical Report STR97/08, GeoForschungsZentrum Potsdam.

Höpfner, J., 1998a. Seasonal length-of-day changes and atmospheric-angular-momentum oscillations in their temporal variability, Scientific Technical Report STR98/10, GeoForschungsZentrum Potsdam.

Höpfner, J., 1998b. Seasonal variations in length-of-day and atmospheric-angular-momentum, GJI, 135, 407-437.

Höpfner, J., 1998c. Variationen in der Tageslänge und dem atmosphärischen Drehimpuls im Zeitbereich von einigen Jahren. In: Progress in Geodetic Science at GW 98. Edited by Willi Freeden. Shaker Verlag, Aachen, 106-113.

Höpfner, J., 1999. Interannual variations in length of day and atmospheric angular momentum with respect to ENSO cycles, Scientific Technical Report STR99/07, GeoForschungsZentrum Potsdam.

Höpfner, J. 2000. Seasonal length-of-day changes and atmospheric angular momentum oscillations in their temporal variability. J. Geodesy, 74, 335358.

Johnson, T. J., Wilson, C. R. and Chao, B. F., 1999. Oceanic angular momentum variability estimated from the Parallel Ocean Climate Model, 19881999. J. Geophys. Res., 104, B11(25), 183-195.

Marcus, S. L., Chao, Y., Dickey, J. O. and Gegout, P., 1998. Detection and modeling of nontidal oceanic effects on Earth's rotation rate. Science, 281, 1656-1659.

Naito, I. and Kikuchi, N., 1990. A seasonal budget of the Earth's axial angular momentum. Geophys. Res. Lett., 17, 631-634.

Ponte, R. M., 1990. Barotropic motions and the exchange of angular momentum between the oceans and the solid Earth. J. Geophys. Res., 95, 1136911374.

Ponte, R. M., 1997. Oceanic excitation of daily to seasonal signals in Earth rotation: Results from a constant-density numerical model. Geophys. J. Int., 130, 469-474.

Rosen, R. D., 1993. The axial momentum balance of Earth and its fluid envelope. Surv. Geophys., 14, 1-29.

Rosen, R. D. and Salstein, D. A., 1991. Comment on "A seasonal budget of the Earth's axial angular momentum" by Naito and Kikuchi. Geophys. Res. Lett., 18, 1925-1926.

Thomas, M. and Sündermann, J., 1998. Zur simultanen Modellierung von allgemeiner Zirkulation und Gezeiten im Ozean und Auswirkungen auf bestimmte Erdrotationsparameter. In: Freeden, W. (ed.), Progress in Geodetic Science at GW 98. Shaker Verlag, Aachen, $144-151$.

Thomas, M. and Sündermann, J., 2000. Numerical simulations of ocean induced variations of Earth's rotation. In: Soffel, M. and Capitaine, N. (ed.), Motion of celestial bodies, astrometry and astronomical reference frames. Proceedings of the Les Journes 1999 \& IX. Lohrmann-Kolloquium. Published by Paris Observatory, 167-169.

Whitworth, T. and Peterson, R. G., 1985. Volume transport of the Antarctic Circum-Polar Current from bottom pressure measurements. J. Phys. Oceanogr., 15, 810-816.

Willmott, C. J., Rowe, C. M. and Mintz, J., 1985. Climatology of the terrestrial seasonal water cycle. J. Climatol., 5, 589-606. 